\title{
Shunt portossistêmico extra-hepático em cadela maltês de 8 meses
}

\section{Extrahepatic portosystemic shunt in a 8 month-old female maltese dog}

\author{
Rafaella Cristina Reginatto ${ }^{1}$; Michele Salmon Frehse ${ }^{2 *}$; Neide Mariko Tanaka ${ }^{3}$; \\ Vinicius Fávero ${ }^{1}$; Gisele Sprea ${ }^{4}$; Fernando Swiech Bach ${ }^{4}$; Marcelus Natal Sanson ${ }^{4}$
}

\section{Resumo}

O shunt portossistêmico ou desvio portossistêmico (DPS) são comunicações vasculares únicas ou múltiplas entre a circulação sistêmica e a circulação portal, que permite que o sangue portal chegue ao sistema circulatório sem antes passar pela metabolização hepática. Podem ser adquiridos ou congênitos e também podem ser classificados como intra-hepático, localizado dentro do fígado, ou extra-hepático, localizado fora do parênquima hepático. A forma adquirida normalmente está associada com distúrbios intra-hepáticos. Eles normalmente sugerem vasos tortuosos que se comunicam com a veia cava caudal na região do rim esquerdo. A forma congênita está associada a genética e uma das linhagens mais acometidas é a raça maltês. O presente relato de caso descreve o diagnóstico e tratamento de uma cadela maltês de oito meses de idade com Shunt portossistêmico extra-hepático. A paciente apresentava sinais de encefalopatia hepática, como: inquietação, locomoção apoiando-se nas paredes, compressão da cabeça contra a parede, tremores de cabeça e deficiência visual. Exames complementares constataram: glicemia pós-prandial próximo do valor inferior de referência, fosfatase alcalina (FA) e alanina aminotransferase (ALT) aumentadas e hipoalbuminemia. A ultra-sonografia revelou a presença de cálculo vesical e cálculo renal bilateral, fígado diminuído e aumento da ecogenicidade, vesícula biliar com conteúdo anecóico e alta celularidade podendo sugerir hepatopatia/ colangiohepatopatia e detectou DPS extra-hepático. O uso do Doppler auxiliou na localização do desvio identificando a comunicação e a turbulência certificando-se do DPS extra-hepático. Dieta com restrição protéica e antibioticoterapia com amoxicilina obtiveram bons resultados. Optou-se em fazer apenas o tratamento clínico e manter a qualidade de vida da paciente.

Palavras-chave: Shunt portossistêmico. Maltês. Diagnóstico. Tratamento.

\begin{abstract}
The shunt portosystemic or portosystemic deviation (PSD) are unique or multiples vascular communications between the systemic circulaton and the portal circulation, that permit blood flow reaches the circulatory system without first passing trhought the hepatic metabolization. May be acquired or congenital and can also be classified as intrahepatic located within the liver or extrahepatic located outside the liver parenquima. The acquired form is usually associated with intra-hepatic disorders. They usually suggest tortuous vessels that communicate with the caudal vena cava in the region of the left kidney. The congenital form is associated with genetic lineage and one of the most affected is Maltese breed. This case report describes the diagnostis and treatment of a eight year-old female Maltese dog
\end{abstract}

1 Médicos Veterinários Autônomos, Curitiba-PR. E-mail: rafareginatto@hotmail.com; vinicius_favero@hotmail.com

2 Médica Veterinária, M.Sc. Doutoranda da Universidade Estadual de Londrina, UEL, Londrina, PR. E-mail: mi_uel2003@yahoo. com.br

3 Médica Veterinária, PhD, Prof da Universidade do Norte do Paraná, UNOPAR. Arapongas, PR. E-mail: nmtanaka@onda.com. br

4 Médicos Veterinários Hospital Veterinário Clinivet, Curitiba, PR. E-mail: gisprea@gmail.com; neurologia@clinivet.com.br; marcelus@clinivet.com.br

* Autor para correspondência 
presenting extrahepatic Portosystemic Shunt. The patient showed signs of hepatic encephalopathy, such as restlessnees, weakness, deambulation, head tremor and impaired visual. Complementary exam demonstrated: postprandial glicemia near the lower limit of reference, alkaline phosphatase (ALP) and alanine aminotransferase (ALT) increased and hipoalbuminemia. Ultrasonography revealed the presence of vesical calculus and bilateral kidney, liver decreases and increased echogenicity, gallbladder with anechoic content and high cellularity may suggest liver/ colangiohepatopatia and extrahepatic DPS was detected. The use of Doppler assisted in identifying the location of the bypass communication and the turbulence detecting the extrahepatic DPS. Protein-restricted diet and antibiotic therapy with amoxicillin achieved good results. The clinical treatment was decided make only the clinical and maintain the quality of life of the patient.

Key words: Portosystemic shunt. Maltese. Diagnosis and treatment.

\section{Introdução e Revisão de Literatura}

O shunt portossistêmico ou desvio portossistêmico (DPS) são comunicações vasculares únicas ou múltiplas entre a circulação sistêmica e a circulação portal, que permite que o sangue portal chegue ao sistema circulatório sem antes passar pela metabolização hepática (MURPHY; ELLISON; LONG, 2001; JOHNSON, 2004; FOSSUM, 2005; BUNCH, 2006; BRUM et al., 2007).

O fluxo sanguíneo hepático diminuído e a falta de substâncias hepatotrópicas provenientes do pâncreas e intestino tais como:, insulina, glucagon e nutrientes não atingem o fígado e resultam em atrofia hepática. O sangue da veia porta que passa direto para a circulação sistêmica sem sofrer detoxificação hepática leva a encefalopatia hepática (EH) (MURPHY; ELLISON; LONG, 2001; JONHSON, 2004; FOSSUM, 2005; BUNCH, 2006; BRUM et al., 2007). Segundo Fossum (2005) a EH é uma síndrome clínica de alteração da função do sistema nervoso central, resultante da insuficiência hepática.

Os DPS podem ser adquiridos ou congênitos e também podem ser classificados como intrahepático, localizado dentro do fígado, ou extrahepático, localizado fora do parênquima hepático (JONHSON, 2004; FOSSUM, 2005; BUNCH, 2006).

De acordo com Johnson (2004) a forma adquirida normalmente está associada com distúrbios intrahepáticos, caracterizando vasos tortuosos que se comunicam com a veia cava caudal na região do rim esquerdo. O DPS adquirido está presente devido à hipertensão portal (HP) e está associado a algumas doenças como: colangiohepatite crônica, neoplasias hepáticas e fístulas arteriovenosas (AV) (JOHNSON, 2004; CARVALHO; CHAMMAS, 2008). A HP é causada pelo aumento de fluxo sanguíneo portal ou aumento da resistência a esse fluxo. Esse aumento de resistência é mais comum devido a doença adquirida (BUNCH, 2004).

O DPS congênito é o mais comumente encontrado, são vasos embrionários anômalos que aparecem como desvios simples (intra ou extrahepáticos), não estando associado a HP(JOHNSON, 2004; CARVALHO; CHAMMAS, 2008).

A forma congênita pode estar associada à genética, as linhagens mais acometidas são de yorkshire terrier, maltês, schnauzer miniatura, old english sheepdog, irish wolfhounds (JOHNSON, 2004; van STEENBEEK, 2009).

Acomete normalmente os cães de raças puras e gatos mestiços, entre um mês e 12 anos de idade (BUNCH, 2006; CARVALHO; CHAMMAS, 2008).

Para Fossum (2005), o DPS intra-hepático é mais comum em raças de grande porte e fornecem uma comunicação entre a veia porta e a veia cava caudal, que ocorre por falha do ducto venoso em se fechar após o nascimento (JOHNSON, 2004; FOSSUM, 2005; BRUM et al., 2007; BUNCH, 2006).

O DPS extra-hepático normalmente conecta a veia porta ou veia gástrica esquerda ou veia esplênica com a veia cava cranial caudal às veias 
frênico-abdominais. Com menor frequência os vasos anômalos entram na veia ázigo ou em outro vaso sistêmico (JOHNSON, 2004; FOSSUM, 2005; BUNCH, 2006). O DPS extra-hepático ocorre principalmente em raças de pequeno porte (JOHNSON, 2004; FOSSUM, 2005; BUNCH, 2006; BRUM et al., 2007). Van Straten et al. (2005) confirmaram a expressão hereditária autossomal e provável poligênica do shunt portossistêmico extrahepático congênito em Cairn Terriers.

Os sinais clínicos do DPS dependem da cronicidade do distúrbio e estão relacionados com o sistema nervoso central, gastrintestinal e trato urinário. No DPS adquirido e congênito os sinais se manifestam de maneira igual, normalmente apresentam EH que pode incluir anormalidades neurocomportamentais, sinais neurológicos, ataxia, pressão da cabeça contra a parede, desorientação, vocalização, convulsão, cegueira, anorexia, perda de peso, apatia, vômito, ascite, diarréia, dor abdominal, uropatia obstrutiva devido à urolitíase por biurato de amônio, poliúria, polidipsia, hematúria e polaciúria (MURPHY; ELLISON; LONG, 2001; JOHNSON, 2004). A ascite é mais comum na forma adquirida, pois a HP é o mecanismo de formação do desvio (JOHNSON, 2004).

A EH é mais comumente vista no DPS congênito e os seus sinais tendem a aumentar e diminuir, podendo estar intercalada com períodos normais, ela tende a acentuar após a ingestão de alimentos com altos níveis de proteínas, pelo sangramento gastrintestinal associado a parasitas, transfusão contendo altas concentrações de amônia, alcalose metabólica que favorece a formação da amônia, constipação, hipocalemia que aumenta a produção renal de amônia e terapia medicamentosa com alguns anestésicos, anti-histamínicos e tetraciclinas (JOHNSON, 2004; BUNCH, 2006).

No hemograma poderão ser vistas algumas alterações, como anemia arregenerativa leve a moderada e microcitose podendo estar associada ao metabolismo anormal de ferro (MURPHY;
ELLISON; LONG， 2001; JOHNSON， 2004; FOSSUM, 2005).

Os testes bioquímicos revelam hipoproteinemia, diminuição de nitrogênio uréico sérico (BUN), hipoalbuminemia, hipoglobulinemia, hipocolesterolemia, hipoglicemia, pequeno aumento de ALT e FA (MURPHY; ELLISON; LONG, 2001; JOHNSON, 2004; FOSSUM, 2005; BUNCH, 2006).

A urinálise pode revelar a presença de cristais de biurato de amônia e urina diluída. Devido à inflamação e infecção mecânicas secundárias aos cálculos metabólicos pode-se ter hematúria, piúria e proteinúria. A função hepática pode ser avaliada também através do teste de ácidos biliares séricos (ABS) ou através do teste de tolerância à amônia. O ABS pode ser feito para o diagnóstico do DPS, onde em jejum quase sempre estarão aumentados, mas podem estar normais também. O ABS pós-prandiais quando estão acentuadamente

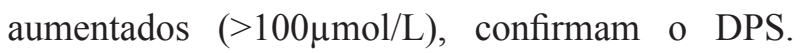
$\mathrm{O}$ teste de tolerância à amônia é o método mais confiável de demonstrar hiperamonemia, porém não é muito utilizado devido à restrição de transporte e manuseio do sangue (JOHNSON, 2004; FOSSUM, 2005; PEREIRA et al., 2008).

O achado mais compatível em radiografias é a microhepatia ou cálculos urinários. Os cálculos de urato de amônio não são visíveis, a menos que eles contenham quantidades significativas de magnésio e fosfato (JOHNSON, 2004; FOSSUM, 2005).

A ultra-sonografia e a cintilografia fornecem informações sobre a presença, a localização e o tipo de DPS. A ultra-sonografia detecta de maneira mais confiável os DPS intra-hepáticos do que os extrahepáticos, o fígado normalmente aparece pequeno, apresenta hipovascularidade e o vaso do desvio pode ser identificado e na avaliação dos rins e da bexiga podem-se encontrar cálculos. Identificam-se ainda os vasos tortuosos e anecóicos observados junto com fístulas AV hepáticas (MURPHY; ELLISON; LONG, 2001; JOHNSON, 2004; FOSSUM, 2005). 
O ultra-som com Doppler colorido tem sido um método útil de diagnóstico, ele auxilia na localização do desvio, examina a veia cava caudal à veia frênico-abdominal e a junção com a veia cava, no local da comunicação ocorre turbulência garantindo a anomalia vascular portossistêmica extra-hepática (CARVALHO; CHAMMAS, 2008).

A cintilografia portal é uma técnica para os animais que apresentam sinais inespecíficos de DPS, monitora o fechamento do desvio no pós-operatório e registra o fluxo sanguíneo hepático anormal, fornecendo o cálculo da fração do desvio a partir de gráficos da atividade com o tempo, é administrado pela via retal o pertecnetato $99 \mathrm{~m}$ tecnécio, onde é rapidamente absorvido do cólon para o sangue portal, nos animais normais a radioatividade é detectada primeiro no fígado e depois no coração, no DPS ela alcança o coração antes ou ao mesmo tempo em que alcança o fígado (JOHNSON, 2004; FOSSUM, 2005; PEREIRA et al., 2008).

Nos animais que apresentam EH, o tratamento consiste em fluidoterapia com solução fisiológica e suplementação de potássio conforme a necessidade para corrigir as anormalidades eletrolíticas e ácidobásicas, dieta altamente digerível com restrição protéica, sendo o carboidrato a fonte primária de calorias, deve-se usar dietas formuladas comercialmente para doenças hepáticas ou insuficiência renal, antibióticos como metronidazol, ampicilina e neomicina sendo esta a mais utilizada, onde irão reduzir a flora intestinal na produção de toxinas como amônia. A lactulose também é utilizada por via oral ou através de enema, a finalidade é acidificar o lúmen intestinal impedindo a produção e absorção de amônia (MURPHY; ELLISON; LONG, 2001; JOHNSON, 2004; FOSSUM, 2005; BUNCH, 2006; BRUM et al., 2007; PEREIRA et al., 2008).

De acordo com Bunch (2006) a dieta pode ser preparada em casa pelo proprietário, utilizando proteína a base de leite, tais como queijo cottage, proteínas a base de ovo, soja, frutas e vegetais.
Para o DPS congênito o tratamento definitivo é cirúrgico, através da ligação cirúrgica da anomalia vascular portossistêmica ou o emprego de um constritor ameróide (MURPHY; ELLISON; LONG, 2001; JOHNSON, 2004; FOSSUM, 2005). A ligação cirúrgica tem como objetivo a ligação total, mas frequentemente atinge-se apenas a ligação parcial por motivo de segurança, devido a risco de HP. O volume de sangue portal que é desviado de volta para o fígado após a ligação total é muito grande, fazendo com que o fígado não consiga acomodar esse volume a mais e desenvolva a HP (MURPHY; ELLISON; LONG, 2001; JOHNSON, 2004; PEREIRA et al., 2008).

Segundo Johnson (2004) e Hunt et al. (2004) a HP pode ocorrer de duas e 24 horas após a realização da cirurgia. Os sinais que serão observados caso isso ocorra são distensão abdominal, dor, diarréia sanguinolenta, íleo paralítico, choque endotóxico e colapso cardiovascular hiperagudo. Se houver HP grave, o animal deve ser submetido à laparotomia de emergência, removendo a ligadura.

Convulsões e estado epilético são as complicações pós-operatória da ligação cirúrgica (JOHNSON, 2004; BUNCH, 2006). Para Johnson (2004) essas convulsões não possuem como causa só a hipoglicemia ou $\mathrm{EH}$ e sim pelo simples fato de o cérebro ter se adaptado ao metabolismo alterado.

O constritor de ameróide reduz os riscos cirúrgicos imediatos da ligação, é um material higroscópico em anel de aço inoxidável, que é colocado ao redor do desvio e conforme o fluido é absorvido o lúmen do anel se torna menor, ocluindo o desvio (MURPHY; ELLISON; LONG, 2001; JOHNSON, 2004; FOSSUM, 2005; PEREIRA et al., 2008).

Faixas de celofane atualmente têm sido usadas para a oclusão do DPS, essas fitas possuem o mesmo efeito do anel de ameróide e são colocadas ao redor do shunt induzindo um processo lento e progressivo de oclusão (FOSSUM, 2005; HUNT et al., 2004).

Segundo Murphy, Ellison e Long (2001) e 
Johnson (2004) esses métodos possuem como vantagens a oclusão progressiva do desvio até o período de 30 a 60 dias, a diminuição do tempo cirúrgico e anestésico e ausência de monitoração da pressão portal durante a cirurgia.

Os desvios intra-hepáticos são mais difíceis de corrigir do que os desvios extra-hepáticos (JOHNSON, 2004).

O prognóstico para os animais submetidos à ligação cirúrgica total e que sobrevivem ao póscirúrgico imediato é excelente, ocorrendo melhora de 70 a $80 \%$ dos sinais clínicos. Nos casos de ligação parcial o prognóstico não é tão bom, os sinais clínicos podem desaparecer nos primeiros anos, mas cerca de 40 a $50 \%$ reaparecem com os sinais. O acompanhamento pós-cirúrgico deve ser feito por três anos. Para alguns pacientes deve ser feito o tratamento para a EH pela vida inteira (JOHNSON, 2004).

De acordo com Bunch (2006) um terço de todos os animais que apresentam o DPS optam em fazer apenas o tratamento clínico e podem ter uma boa qualidade de vida, que vai de tres a oito anos. Alguns desses animais necessitam ser submetidos a eutanásia dentro de 10 meses por apresentarem EH incontrolável.

\section{Relato do Caso}

Uma cadela da raça maltês, oito meses de idade, $1,5 \mathrm{Kg}$ foi atendida no Hospital Veterinário Clinivet, Curitiba-PR. De acordo com o histórico clínico, a paciente recebeu vacina anti-rábica e cerca de três horas após a administração da mesma percebeu que a paciente estava inquieta, se locomovia apoiando- se nas paredes, fazia compressão da cabeça contra a parede, apresentava tremores de cabeça e deficiência visual. As demais funções fisiológicas dentro da normalidade.

Ao exame neurológico observou perambulações, andar em círculo para ambas as direções apoiando-se na parede, movimentos ligeiramente hipermétricos, tremor de intenção de cabeça acentuado, sialorréia, resposta pupilar direta e consensual normal e deficiência ao teste de ameaça bilateral.

A paciente foi internada para acompanhamento dos sinais e para a realização de exames complementares. A dosagem de glicemia pósprandial foi de $64 \mathrm{mg} / \mathrm{dL}$. Diazepam $0,02 \mathrm{mg} / \mathrm{kg}$ foi administrado para minimizar a agitação tônico clônica, após o retorno da sedação a paciente permaneceu sonolenta, mas com melhora dos sinais neurológicos.

Exames bioquímicos demonstraram: creatinina 0,47mg/dL e ALT 746,3U/L. No hemograma, hemoglobina $11,4 \mathrm{~g} / \mathrm{dL}$, leucocitose, segmentados $19.068 \mathrm{~mm}^{3}$, e proteína plasmática $4,6 \mathrm{~g} / \mathrm{dL}$. A glicemia foi repetida em jejum e o valor estava dentro da normalidade. Dosagem de amônia $(150,3 \mathrm{MOL} / \mathrm{L})$ e a fosfatase alcalina $(510,9 \mathrm{UI} / \mathrm{L})$, estavam acima dos valores normais de referência, e observou uma hipoalbuminemia de 1,84g/dL.

$\mathrm{Na}$ ultra-sonografia abdominal exploratória identificou-se a presença de cálculo vesical e cálculo renal bilateral, fígado diminuído e aumento da ecogenicidade, vesícula biliar com conteúdo anecóico e alta celularidade (Figura 1) podendo sugerir hepatopatia/ colangiohepatopatia. 


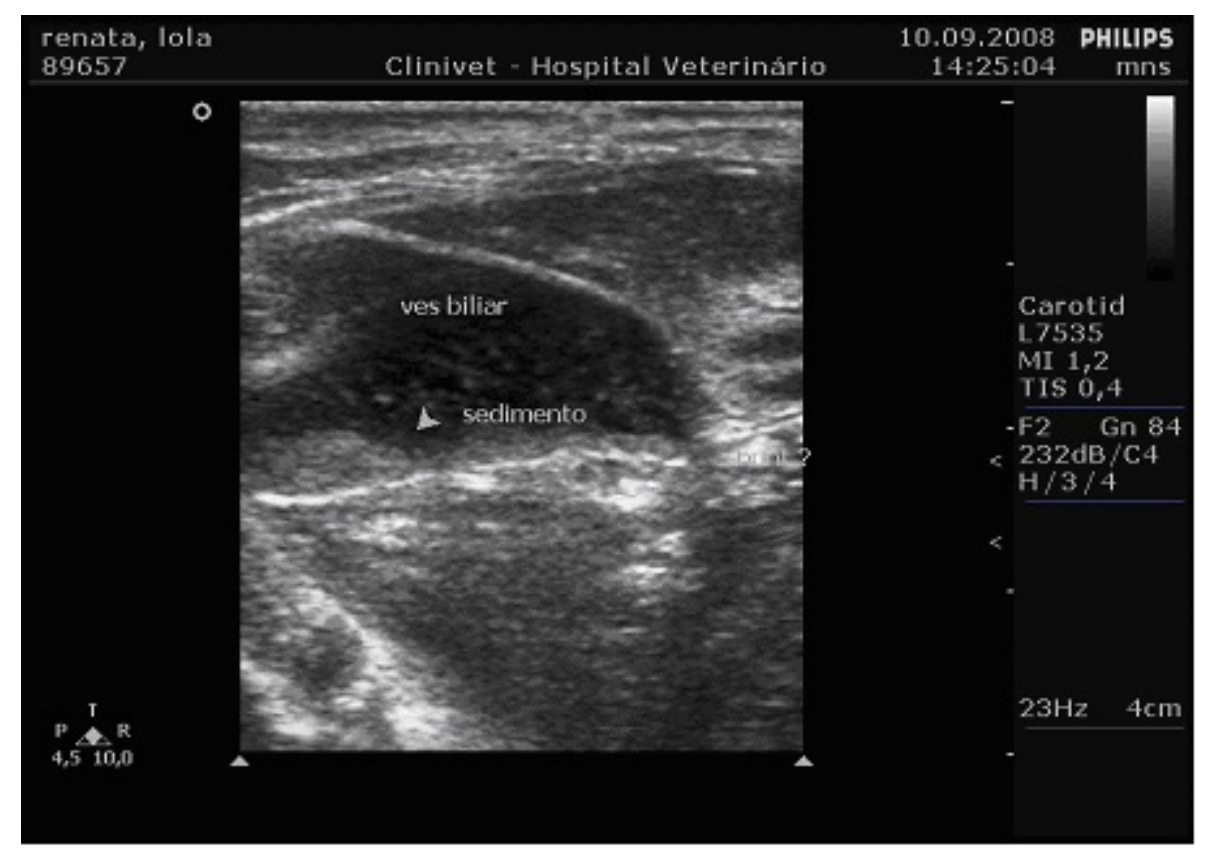

Figura 1. Imagem ultra-sonográfica - sedimento em vesícula biliar.

Na avaliação vascular com Doppler colorido, foi entre veia porta e veia cava caudal em abdome observado fluxo turbulento e provável comunicação direito (Figura 2), sugerindo Shunt Portossistêmico.

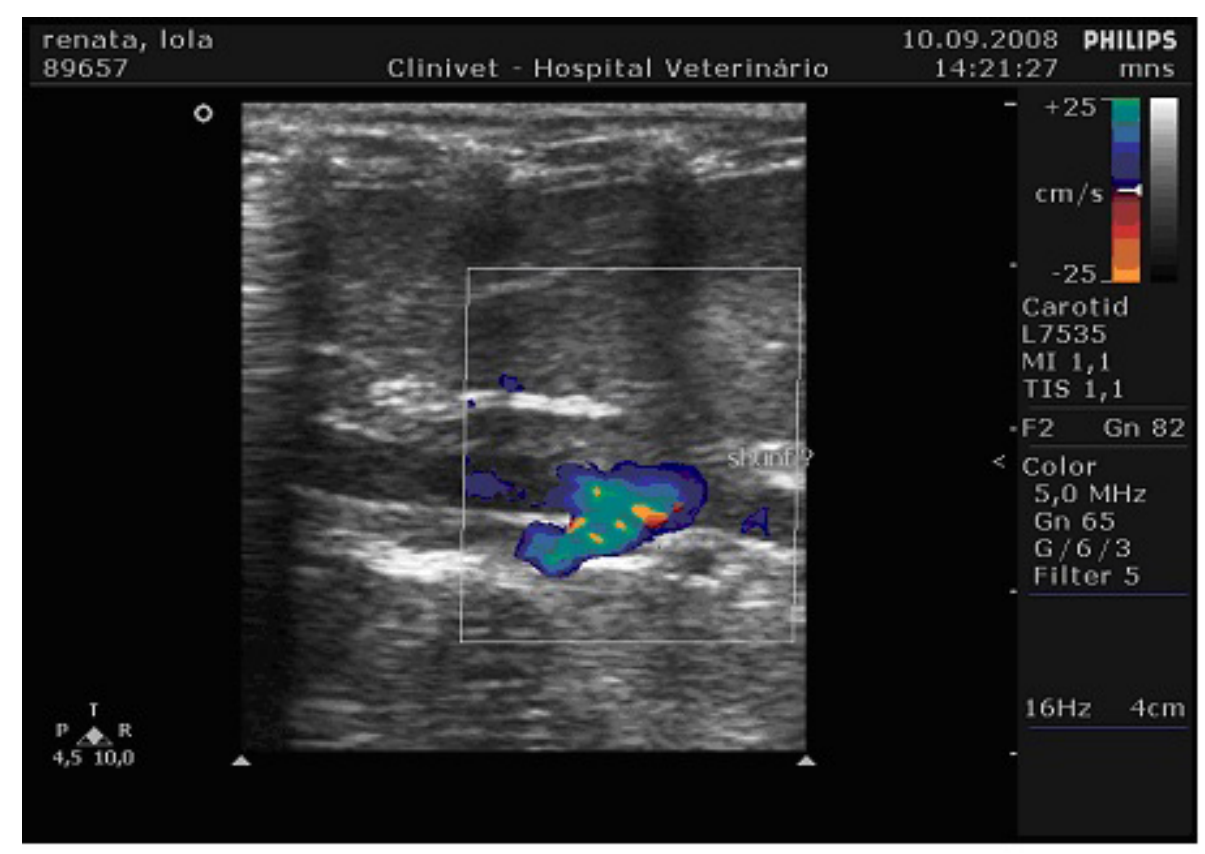

Figura 2. Imagem Doppler colorido - comunicação entre veia porta e veia cava caudal

A paciente recebeu alta médica em bom estado geral e sem alterações neurológicas, foi prescrito amoxicilina $250 \mathrm{mg}$ na dose de $20 \mathrm{mg} / \mathrm{Kg}$ a cada 12 horas durante 20 dias e Legalon ${ }^{\circledR} 10 \mathrm{mg}$ suspensão a cada oito horas durante 30 dias. Foi indicada dieta terapêutica Hepatic da Royal Canin e comida caseira (ricota, queijo branco, carne branca, clara de ovo e arroz). 
Após o período de tratamento, a paciente estava ativa, com apetite e normodipsia. Apresentou apenas um episódio de diarréia pastosa poucos dias após a alta médica com melhora espontânea. Ausência de alterações comportamentais, neurológicas e sialorréia.

A paciente retornou para a realização da urinálise, no resultado a concentração urinária era de 1036, discretamente turva, com traços de proteína e cristais. Apresentava hipoalbuminemia $(1,89 \mathrm{~g} / \mathrm{dL}) \mathrm{e}$ aumento da FA $(299,7 \mathrm{UI} / \mathrm{L})$. Foi prescrito Ursacol ${ }^{\circledR}$ $50 \mathrm{mg}$ a cada 12 horas, até novas recomendações. A paciente apresentava-se em bom estado geral.

\section{Resultados e Discussão}

A paciente da raça maltês apresenta DPS extrahepático. De acordo com Johnson (2004), a forma congênita está associada a genética e uma das linhagens mais acometidas é a maltês. Também, pelo fato de ser um animal de raça pura e com oito meses idade, aumentam as possibilidades de ser extra-hepático (BUNCH, 2006; CARVALHO; CHAMMAS, 2008).

A paciente apresentava sinais clínicos de EH que é mais comumente vista em desvios extra-hepáticos congênitos (MURPHY; ELLISON; LONG, 2001; JOHNSON, 2004).

A glicemia pós-prandial es.tava próximo do valor inferior de referência, FA e a ALT estavam acima dos valores normais de referência e apresentava uma hipoalbuminemia.

De acordo com vários autores, os animais com DPS podem apresentar hipoalbuminemia, pequenos aumentos de FA e ALT e hipoglicemia (MURPHY; ELLISON; LONG, 2001; JOHNSON, 2004; FOSSUM, 2005; BUNCH, 2006).

A urinálise apresentou densidade de 1040 e presença de cristais, com traços de proteínas, além da inflamação e infecção o quadro foi sugestivo de proteinúria. A paciente apresentou uma hiperamonemia, os autores relatam que esse teste é difícil de ser realizado devido a restrição do transporte e do manuseio, mas nesse caso foi feito (JOHNSON, 2004; FOSSUM, 2005; PEREIRA et al., 2008).

A radiografia não foi realizada. Os achados mais significativos no exame radiográfico são os cálculos, sendo que o principal cálculo presente no DPS é o cálculo de urato de amônio (JOHNSON, 2004; FOSSUM, 2005).

Apesar da ultra-sonografia detectar mais os DPS intra-hepáticos, neste caso identificou-se o desvio extra-hepático. As alterações eram compatíveis com a literatura, como diminuição do tamanho do fígado, cálculo vesical e renal bilateral (MURPHY; ELLISON; LONG，2001; JOHNSON，2004; FOSSUM, 2005).

Outro método útil para o diagnóstico é o uso do Doppler (CARVALHO; CHAMMAS, 2008). $\mathrm{Na}$ paciente em questão, o Doppler auxiliou na localização do desvio identificando a comunicação e a turbulência certificando-se do DPS extra-hepático.

A cintilografia portal é uma técnica para os animais que apresentam sinais inespecíficos de DPS (JOHNSON, 2004; FOSSUM, 2005; PEREIRA et al., 2008). Como a paciente apresentava EH, alterações nos exames compatíveis com o desvio e um diagnóstico confirmado através do ultra-som com o Doppler, não seria necessário a realização desse exame.

A paciente recebeu fluidoterapia, dieta com restrição protéica e antibioticoterapia. De acordo com os autores, os antibióticos que devem ser utilizados nesse caso são metronidazol, ampicilina e neomicina, mas no caso da paciente foi utilizado a amoxicilina e foi obtido um bom resultado (MURPHY; ELLISON; LONG, 2001; JOHNSON, 2004; FOSSUM, 2005; BUNCH, 2006; BRUM et al., 2007; PEREIRA et al., 2008).

Para Bunch (2006) a dieta caseira é também uma alternativa de restrição de proteína e foi indicada 
para a proprietária a realização da mesma com ricota, queijo branco, carne branca, clara de ovo e arroz.

O mais indicado para o DPS congênito é o tratamento cirúrgico, mas de acordo com Bunch (2006) em um terço dos animais que apresentam DPS, os proprietários optam em fazer apenas o tratamento clínico.

\section{Conclusão}

Conclui-se que os métodos diagnósticos eficazes e o uso do Doppler colorido auxiliaram no diagnóstico e identificação do DPS extra-hepático o que corroborou para indicar e manter a terapêutica conservadora.

\section{Agradecimentos}

Hospital Veterinário Clinivet, Curitiba-PR.

\section{Referências}

BRUM, A. M. de; CHAMPIO, T.; ZANATTA, R.; COSTA, M. T.; CANOLA, J. C. Utilização de probiótico e de lactulose no controle de hiperamonemia causada por desvio vascular portossistêmico congênito em um cão. Ciência Rural, Santa Maria, v. 37, n. 2, p. 572-574, mar/ abr. 2007.

BUNCH, S. E. Distúrbios hepáticos agudos e sistêmicos que acometem o fígado. In: ETTINGER, S. J.; FELDMAN, E. C. Tratado de medicina interna veterinária. 5. ed. Rio de Janeiro: Guanabara, 2004. p. 1398- 1413.

Doenças hepatobiliares no cão. In: NELSON, R. W.; COUTO, C. G. Medicina interna de pequenos animais. 3. ed. Rio de Janeiro: Elsevier, 2006. p. 507525 .

CARVALHO, C. F.; CHAMMAS, M. C. Uso do ultrassom dúplex Doppler no diagnóstico de shunt portossistêmico em gatos. Arquivo Brasileiro de Medicina Veterinária e Zootecnia, Belo Horizonte, v. 60, n. 1, p. 109-112, fev. 2008.

FOSSUM, T. W. Cirurgia hepática. In: . Cirurgia de pequenos animais. 2. ed. São Paulo: Roca, 2005. p. 451-475.
HUNT, G. B.; KUMMELING, A.; TISDALL, P. L.C.; ANDREW, M.; MARCHEVSKY, L.; JULIUS, M.; YOUMANS, K. R.; GOLDSMID, S. E.; BECK, J. A. Outcomes of cellophane banding for congenital portosystemic shunts in 106 dogs and 5 cats. Veterinary Surgery, Hoboken, v. 33, n. 1, p. 25-31. 2004.

JOHNSON, S. E. Hepatopatias crônicas. In: ETTINGER, S. J.; FELDMAN, E. C. Tratado de medicina interna veterinária. 5. ed. Rio de Janeiro: Guanabara, 2004. p. 1369- 1398.

MURPHY, S. T.; ELLISON, G. W.; LONG, M. A. A comparison of the ameroid constrictor versus ligation in the surgical management of single extrahepatic portosystemic shunts. Journal of American Animal Hospital Association, Lakewood, v. 37, n. 4, p. 390-396. 2001.

PEREIRA, C. T.; MARQUES, F. L.; KERLARRY, A.; JULY, J. R.; MARTINS, B. W. Shunt portossistêmico: considerações sobre diagnóstico e tratamento. Clínica Veterinária, São Paulo, v. 13, n. 72, p. 28-34, jan./fev. 2008.

Van STRATEN, G.; LEEGWATER, P. A. J.; VRIES, M. van den BROM, W. E.; ROTHUIZEN, J. Inherited congenital extrahepatic portosystemic shunts in cairn terriers. Journal of Veterinary Internal Medicine, Hoboken, v. 19, n. 3, p. 321-324. 2005.

Van STEENBEEK, F. G.; LEEGWATER, F. J.; van SLUIJS, F.J .; HEUVEN, H. C. M.; ROTHUIZEN, J. Evidence of inheritance of intrahepatic portosystemic shunts in Irish Wolfhouds. Journal of Veterinary Internal Medicine, Hoboken, v. 23, n. 4, p. 950-952, jul./aug. 2009. 